\title{
Hsp70 (HSP70A1A) downregulation enhances the metastatic ability of cancer cells
}

\author{
PANAGIOTA KASIOUMI $^{1 *}$, PARASKEVI VRAZELI ${ }^{1 *}$, PATRA VEZYRAKI $^{2}$, STELIOS ZERIKIOTIS $^{2}$, \\ CHRISTOS KATSOURAS ${ }^{3}$, ALEXANDER DAMALAS ${ }^{4}$ and CHARALAMPOS ANGELIDIS ${ }^{1}$
}

\author{
Departments of ${ }^{1}$ General Biology, ${ }^{2}$ Physiology and ${ }^{3}$ Cardiology, Michaelideion Cardiac Centre, Faculty of Medicine, \\ School of Health Sciences, University of Ioannina, 45110 Ioannina, Greece; \\ ${ }^{4}$ Biotechnology and Nanomedicine Laboratory, University of Copenhagen, 2200 Copenhagen, Denmark
}

Received May 24, 2018; Accepted November 16, 2018

DOI: $10.3892 /$ ijo.2018.4666

\begin{abstract}
Heat shock protein 70 (Hsp70; also known as HSP70A1A) is one of the most induced proteins in cancer cells; however, its role in cancer has not yet been fully elucidated. In the present study, we proposed a hypothetical model in which the silencing of Hsp70 enhanced the metastatic properties of the HeLa, A549 and MCF7 cancer cell lines. We consider that the inability of cells to form cadherin-catenin complexes in the absence of Hsp70 stimulates their detachment from neighboring cells, which is the first step of anoikis and metastasis. Under these conditions, an epithelial-to-mesenchymal transition (EMT) pathway is activated that causes cancer cells to acquire a mesenchymal phenotype, which is known to possess a higher ability for migration. Therefore, we herein provide evidence of the dual role of Hsp70 which, according to international literature, first establishes a cancerous environment and then, as suggested by our team, regulates the steps of the metastatic process, including EMT and migration. Finally, the trigger for the anti-metastatic properties that are acquired by cancer cells in the absence of Hsp70 appears to be the destruction of the Hsp70-dependent heterocomplexes of E-cadherin/catenins, which function like an anchor between neighboring cells.
\end{abstract}

Correspondence to: Professor Charalampos Angelidis, Department of General Biology, Faculty of Medicine, School of Health Sciences, University of Ioannina, 45110 Ioannina, Greece

E-mail: chaggeli@cc.uoi.gr

"Contributed equally

Abbreviations: Hsp70, heat shock protein 70 (also known as HSP70A1A); EMT, epithelial-to-mesenchymal transition; poly-hema, poly(2-hydroxyethyl methacrylate)

Key words: heat shock protein 70, HSP70A1A, epithelial-tomesenchymal transition, migration, metastasis, cancer

\section{Introduction}

Heatshock protein 70(Hsp70), used herein todenoteHSP70A1A, is a molecular chaperone, approximately $70 \mathrm{kDa}$, that plays a key role in protein homeostasis (1). Its expression is markedly induced by increased environmental temperature (2-4). Hsp70 usually acts together with co-chaperones, forming protein molecular machines (5-7), and its function is carried out by its monomeric form (8). At the molecular level, Hsp70 participates in protein folding (9), degradation (10) and translocation (11), as well as in single-strand DNA repair mechanisms, both in the nucleus and the nucleolus (12). At the cellular level, Hsp70 has been associated with cell viability $(13,14)$ as well as apoptosis $(15,16)$. Finally, at the organism level, Hsp70 has been linked to several diseases and pathological states, such as neurodegenerative diseases $(17,18)$, cancer $(19,20)$, PTZ kindling (21), cardiovascular conditions (22-24), spinal cord ischemia (25) and inner ear protection from exposure to inaudible low-frequency noise (LFN) (26).

The upregulation of Hsp70 is relatively common in human tumors, and it is often associated with an enhanced resistance to chemotherapy and a poor patient prognosis (27). Indeed, over the past decade, several proposed strategies have documented that chemotherapy sensitizes cells to death via the selective inhibition of Hsp70. Heat shock proteins, such as Hsp70, inhibit apoptosis by direct physical interaction with apoptotic molecules, which are also overexpressed in several tumor cells (28). The selective depletion of the 70-kDa heat shock protein activates a specific tumor cell death pathway (29-31). This cell death, referred to as anoikis, is a special type of apoptosis: It occurs in response to the lack of cell attachment or inappropriate attachment to the extracellular matrix (ECM) and neighboring cells (32). The property of cancer cells to act independently of survival signals and lack of the ability to adhere efficiently are key mechanisms for the transformation of neoplastic into metastatic cells, since it allows malignant cells to detach and migrate from the primary tumor by escaping cell death (33-35). The ability of Hsp70 to suppress apoptosis by interfering with cell pathways is a field of great interest. Significant results were initially provided by a scientific group suggesting that Hsp70 prevents recruitment of procaspase-9 to the apaf-1apoptosome (36). 
Epithelial-to-mesenchymal transition (EMT) is a biological process that allows a polarized epithelial cell to undergo biochemical changes that render it capable of acquiring a mesenchymal phenotype, which includes enhanced migration capacity, invasiveness, an increased resistance to apoptosis and the markedly increased production of ECM components (37). EMT is a critical event in the process of cancer metastasis. In the present study, EMT was considered to be a cellular process that mimics a cancer metastatic step in real tumors. The series of events that occur during metastasis and the implication of Hsp70 are shown in the proposed model of Fig. 8 (lower panel). The model begins with the creation of the primary tumor, followed by cell detachment/anoikis, the acquisition of the mesenchymal cell phenotype, cell migration and, finally, attachment to a new location distant from the primary tumor. The questions posed at this stage are the following: the reasons as to why Hsp70 is highly accumulated in cancer cells, and the potential roles of this protein that render it an important protein in cancer. Based on these questions, it may be hypothesized that the increased expression of Hsp70 is associated with the particular stage of tumor metastasis.

During EMT, the expression of several epithelial proteins, including those that are part of the ligand complexes $(38,39)$, is downregulated. In addition, the whole gene expression pattern is reprogrammed, thus promoting changes in cytoskeletal architecture, mesenchymal cell adhesion and cell interaction with the ECM (40). At the onset of EMT, components of cadherin junctions, tight junctions, desmosomes and gap junctions are destroyed. In addition, several other proteins are relocated to other parts of the cell or are degraded. During the destabilization of adhesions, epithelial E-cadherin undergoes degradation and disappears from the cell membranes (41). Moreover, due to the loss of E-cadherin from the cell junctions, $\beta$-catenin, a well-documented cell adhesion protein, is released from the cell adhesions, degraded, and a small part of it translocates to the nucleus where it transactivates several growth-promoting and antiapoptotic genes (42). In addition, the reduction of E-cadherin during EMT leads to the release of catenin p120 from the junctions and its translocation to the nucleus, where it transactivates several genes (43). The above-mentioned changes increase the motility of individual cells and promote the development of a more invasive phenotype.

During EMT, several proteins are downregulated, such as E-cadherin, or upregulated, such as N-cadherin, vimentin, Slug and occludin, which are also used as EMT markers. It is well-known that E-cadherin is an adhesion molecule whose reduction in expression leads to loosening of cell-to-cell adhesion and increased cell migration (44). Another protein, occludin, stabilizes the dissolution of narrow ligands and desmosomes (39). Due to E-cadherin downregulation, the epithelial cells lose their interactions and transform into mesenchymal cells. Subsequently, new interactions are formed between mesenchymal cells mediated by the $\mathrm{N}$-cadherin protein, which is upregulated in mesenchymal cells. These interactions are weaker compared with the homophilic interactions between E-cadherins, and facilitate cell migration and cancer spread $(45,46)$.

The role of vimentin in cell migration and EMT of epithelial carcinomas is of great interest (47). It is known that the suppression of vimentin expression inhibits carcinoma cell migration and adhesion (48). The intermediate filament protein, vimentin, is an important marker of EMT and a requisite regulator of mesenchymal cell migration (49).

Slug is a transcriptional repressor of E-cadherin and its overexpression promotes the metastasis of cancer cells (50). Finally, occludin is another marker that is important for the induction and establishment of EMT. Moreover, the dissolution of watertight junctions is accompanied by reduced expression of clonidine and occludin proteins and the diffusion of ZO1 (39).

The aim of the present study was to elucidate the role of Hsp70 in the different stages of the metastatic process. It is well known that Hsp70 renders cells resistant to apoptosis by forming a more tumorigenic environment $(15,35)$. In addition, evidence suggests the involvement of Hsp70 in cancer metastasis. Therefore, it is crucial to elucidate whether the absence of Hsp70 promotes cell metastasis by enabling the cancer cells to detach from the tumor and favoring their migration to other parts of the body. In this study, we constructed cancer cell lines in which Hsp70 was stably knocked down, aiming to demonstrate the crucial role of Hsp70 in anoikis, the acquisition of the mesenchymal phenotype and cell migration.

\section{Materials and methods}

Cell culture and heat shock. The cell lines used in the study were MCF7 (acronym of Michigan Cancer Foundation-7, a human breast adenocarcinoma cancer cell line, ATCC ${ }^{\circledR}$ HTB-22 $2^{\mathrm{TM}}$ ), A549 (adenocarcinomic human alveolar basal epithelial cells, ATCC $^{\circledR}$ CCL-185 ${ }^{\mathrm{TM}}$ ) and HeLa (human epithelioid cervical carcinoma cell line, no. CCL 185; ATCC, Rockville, MD, USA). The human MCF7, A549 and HeLa cells were cultured in Dulbecco's modified Eagle's medium with $4.5 \mathrm{~g}$ glucose, $110 \mathrm{mg}$ sodium pyruvate, L-glutamine (Sigma-Aldrich; Merck KGaA, Darmstadt, Germany) supplemented with $10 \%$ fetal bovine serum and $1 \%$ penicillin-streptomycin. The cells were grown and passaged by trypsinization. The cells were grown in a monolayer, as previously described (51). In the case of heat shock, subconfluent cells were exposed to immersing dishes in a water bath set at $43.5^{\circ} \mathrm{C}$ for $90 \mathrm{~min}$ and a recovery period of another $90 \mathrm{~min}$ at $37^{\circ} \mathrm{C}$.

Plasmidconstructionandstablytransfectedcellularclones. The DNA expression vectors pcDNA3 (Invitrogen; Thermo Fisher Scientific, Waltham, MA, USA) and pSuper-siRNA-Hsp70 (52) were used for pcDNA3-siRNA-Hsp70 plasmid preparation. Specifically, the BamHI-KpnI (343 bp) DNA fragment of pSuper-siRNA-Hsp70 was ligated to the BglII (generating compatible ends with the BamHI)-KpnI DNA fragment (4,559 bp) of the pcDNA3 plasmid, creating the 5,902 bp pcDNA3-siRNA-Hsp70. This DNA plasmid contains a siRNA insert, targeting and downregulating Hsp70, under the control of the human $\mathrm{H} 1$ promoter. It also contains an ampicillin and neomycin selection marker, located after the SV40 promoter and ending at poly-A SV40. This construct $(2 \mu \mathrm{g})$ was stably transfected into MCF7, A549 and HeLa cells $\left(5 \times 10^{6}\right)$ in $400 \mu 1$ serum-free medium, with electroporation (GenePulser, Xcell; Bio-Rad Laboratories, Inc., Hercules, CA, USA). Transfected and stable clones were selected, subcloned by limiting dilution 
and maintained in $500 \mu \mathrm{g} / \mathrm{ml}$ of G418. The selection of cells containing stably integrated copies of the transfected plasmid was accomplished by the addition of Geneticin (G-418: BRL-Gibco; Thermo Fisher Scientific, Inc.; 11811-031) to the medium at a concentration of $700-1,000 \mu \mathrm{g} / \mathrm{ml}$.

Antibodies. The antibodies used in our experiments were as follows: Anti-Hsp70 antibody (a mouse monoclonal antibody that specifically binds to human HSP70A1A; dilution, 1:2,500; cat. no. SPA-810; StressGen Biotechnologies Corporation, San Diego, CA, USA); anti- $\alpha$-tubulin antibody (dilution, 1:10,000; cat. no. T5168; Sigma-Aldrich; Merck KGaA); anti-Annexin V-fluorescein isothiocyanate (FITC) antibody (dilution, as proposed by the manufacturer in the staining protocol; cat. no. 556420, BD Pharmigen ${ }^{\mathrm{TM}}$; BD Biosciences, Franklin Lakes, NJ, USA); and anti-occludin antibody (dilution, 1:1,000; cat. no. ab31721, Abcam, Cambridge, UK). The EMT kit (Epithelial-Mesenchymal Transition Antibody Sampler kit \#9782; Cell Signaling Technology, Inc., Danvers, MA, USA,) containing antibodies against $\beta$-catenin (dilution, 1:1,000), E-cadherin (dilution, 1:1,000), N-cadherin (dilution, 1:1,000), vimentin (dilution, 1:1,000) and Slug (dilution, 1:1,000).

Cell extract and western blot analysis. Control and heat-treated cells were harvested, washed with phosphate-buffered saline (PBS; $139 \mathrm{mM} \mathrm{NaCl}, 5.4 \mathrm{mM} \mathrm{KCl}, 0.37 \mathrm{mM} \mathrm{Na}_{2} \mathrm{HPO}_{4}$, $0.44 \mathrm{mM} \mathrm{KH_{2 }} \mathrm{PO}_{4}$ and $4.16 \mathrm{mM} \mathrm{NaHCO}_{3}$ ) and resuspended in RIPA buffer [50 mM Tris- $\mathrm{HCl}(\mathrm{pH} 7.5), 150 \mathrm{mM} \mathrm{NaCl}$, $1 \%$ (v/v) Triton X-100, 1\% (w/v) sodium deoxycolate, $0.1 \%(\mathrm{w} / \mathrm{v})$ sodium dodecyl phosphate (SDS)] supplemented with $1 \mathrm{mM}$ PMSF, $1 \mu \mathrm{g} / \mathrm{ml}$ leupeptin and $1 \mu \mathrm{g} / \mathrm{ml}$ pepstatin. Lysates were prepared as previously described (24) and mixed with SDS sample buffer until 1X final concentration [62.5 mM Tris- $\mathrm{HCl}$, $3 \%(\mathrm{w} / \mathrm{v}) \mathrm{SDS}, 10 \%$ (v/v) glycerol, $5 \%$ (v/v) 2-mercaptoethanol, $0.01 \%(\mathrm{w} / \mathrm{v})$ bromophenol blue]. Prior to use, protein extracts (20 $\mu \mathrm{g} / \mathrm{sample}$ ) were boiled for $3 \mathrm{~min}$ at $95^{\circ} \mathrm{C}$ and analyzed by $10 \%$ SDS-polyacrylamide gel electrophoresis and subsequently by western blot analysis using nitrocellulose membranes (Hybond C, Amersham; GE Healthcare Life Sciences, Little Chalfont, UK). The blots were blocked overnight at $4^{\circ} \mathrm{C}$ and then incubated with the primary antibodies for $1 \mathrm{~h}$ at room temperature, rinsed with Tris-buffered saline/Tween-20 and incubated with peroxidase-conjugated secondary antibodies, specifically with anti-mouse IgG-HRP (cat. no. 31430; dilution, 1:5,000) and anti-rabbit IgG-HRP (cat. no. 31460; dilution, 1:5,000; Pierce/Thermo Fisher Scientific) for $45 \mathrm{~min}$ at room temperature. Protein expression was detected with the enhanced chemiluminescence's method (SuperSignal West Pico, Chemiluminescent Substrate CA 47079; Pierce; Thermo Fisher Scientific, Inc.).

Immunofluorescence-confocal microscopy. The control or heat-shocked $\left(43.5^{\circ} \mathrm{C}, 90 \mathrm{~min}\right)$ parent and stably transfected MCF7, A549 and HeLa cells were grown on coverslips and subjected to indirect immunofluorescence (12). In brief, the cells were washed with PBS, fixed with $2 \%$ formaldehyde for $10 \mathrm{~min}$ and permeabilized for 3-5 min with absolute methanol. The cells were then washed with PBS, incubated in 3\% BSA to prevent non-specific staining and subjected to incubation with the appropriate antibodies. For the Hsp70 scoring, we used $1.5-\mu \mathrm{g}$ anti-Hsp70/ml sample (2\% paraformaldehyde in PBS) containing $1 \times 10^{6}$ cells. Images were captured using a Leica TCS-SP confocal microscope, equipped with an argent-crypt laser and Leica TCS software (Leica Microsystems GmbH, Wetzlar, Germany). The stimulation of FITC and TRITC was achieved using wavelengths of 488 and $568 \mathrm{~nm}$, respectively.

Detection of Hsp70 and apoptosis by flow cytometry. To detect Hsp70 expression in the cell lines, a specific antibody was used that only detects inducible Hsp70 (HSP70A1A). The measurement of apoptosis was performed by flow cytometry and propidium iodide/Annexin V-FITC staining. The cells were processed as previously described (24) and cytometric analysis was performed in a Partec ML flow cytometer (CyFlow ML, Partec, Munster, Germany); the results were analyzed using Partec FloMax software.

Activation of anoikis by poly-2-hydroxyethyl methacrylate (poly-hema). The cells were grown in suspension on plates coated with poly-hema, which prevents cellular attachment, in order to induce anoikis apoptosis in vitro. The lack of cell anchorage leads to decreased cellular development and, eventually, cell death. More specifically, a poly-hema solution $20 \mathrm{mg} / \mathrm{ml}$ in $95 \% \mathrm{EtOH}$, was prepared by stirring for several hours at $50^{\circ} \mathrm{C}$. The empty Petri dishes $(10 \mathrm{~cm})$ were covered by the addition of $4 \mathrm{ml}$ of the poly-hema solution and were allowed to dry. Prior to use, the dishes were sterilized by UV irradiation and washed twice with $5 \mathrm{ml}$ PBS (1X).

Migration and wound healing assays. The wound healing assay is used to measure the metastatic ability of cells in vitro. The cells were seeded in 6 -well plates $\left(0.25 \times 10^{6}\right.$ cells/well $)$. After becoming confluent, the cell monolayer was scratched using a p200 tip. The cells were washed twice with $1 \mathrm{X}$ PBS, new culture medium was added and wound healing was recorded at 12, 24, 48 and $72 \mathrm{~h}$ of culture. For quantification, images of 4 random fields along the scratch were captured. Identical rectangles with a width corresponding to the width of the original scratch were designed in these fields. Migrated cells were counted under an inverted microscope (Eclipse TS100; Nikon Europe B.V., Amsterdam, The Netherlands) and data were normalized to the number of cells migrated in the control (53).

Statistical analysis. Data are expressed as the means \pm standard deviation (SD) and all experiments were performed in triplicate. The determination of statistical significance of the differences in the comparisons of our results was performed using Student's t-tests. For the statistical evaluation of differences between groups, were performed using the one-way analysis of variance model (ANOVA) and Tukey's or Dunn's tests for post hoc comparisons. P-values $<0.05$ were considered to indicate statistically significant differences.

\section{Results}

Downregulation of Hsp70 in cancer cell lines by siRNA technology leads to phenotypic alterations. Stably transfected MCF7, A549 and HeLa cell lines with Hsp70 downregulation were generated by transfection with the electroporation 


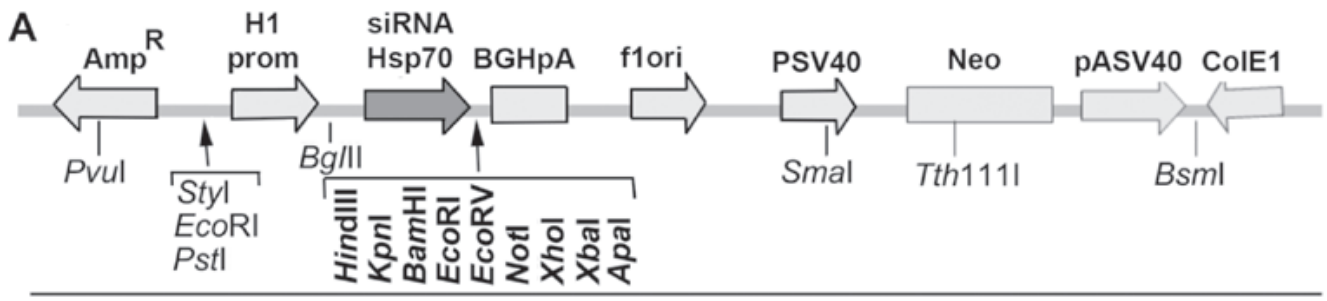

pcDNA3-siRNA-Hsp70 (4.9 Kb)

B

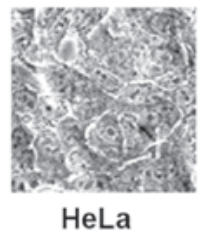

C
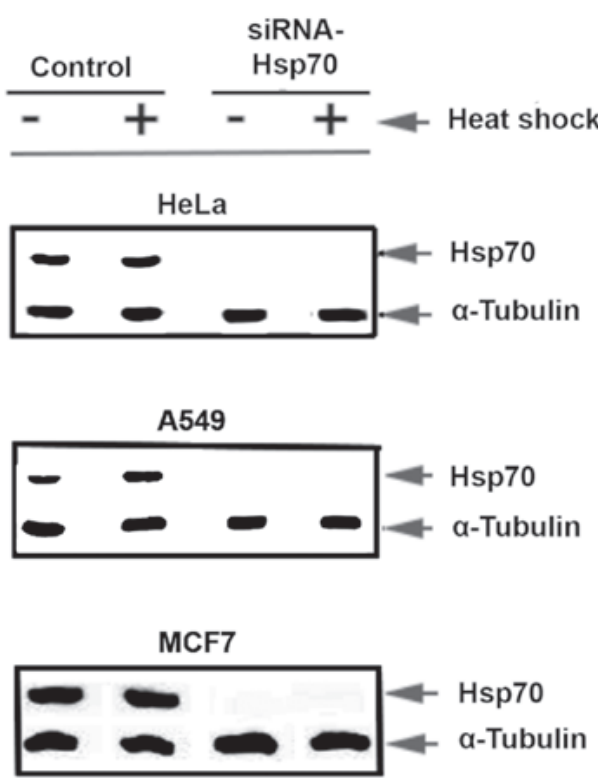
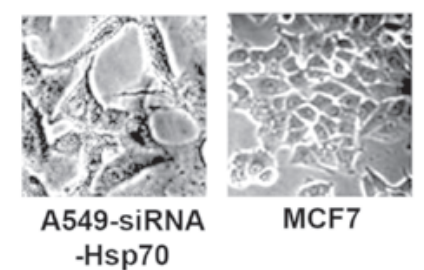

MCF7 -Hsp70

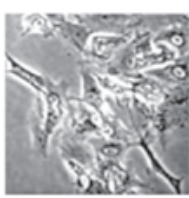

MCF7-siRNA

-Hsp70
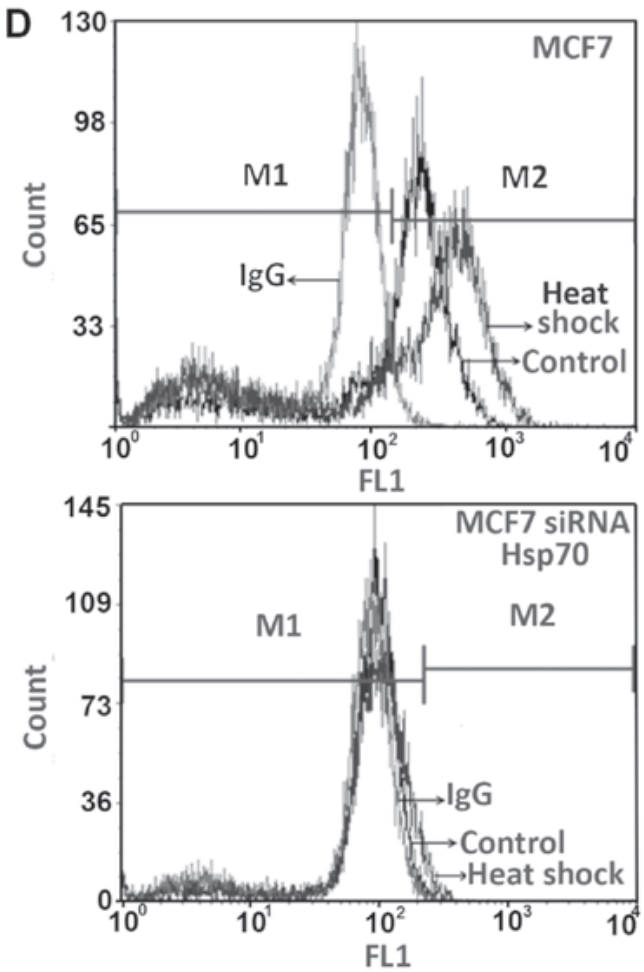

Figure 1. Construction of stably transformed cancer cell lines subjected to Hsp70 gene silencing. (A) HeLa, A549 and MCF-7 cells were transfected with pcDNA3-siRNA-Hsp70 plasmid. Stably transfected cells were isolated using G418 as a selection marker. (B) Cell lines without Hsp70, exhibited a different phenotype similar to that of mesenchymal cells. (C) MCF-7, MCF7-siRNA-Hsp70, A549, A549-siRNA-Hsp70, MCF7 and MCF7-siRNA-Hsp70 cells were heat treated (+) at $41.5^{\circ} \mathrm{C}$ for $120 \mathrm{~min}$ with 90 min recovery at $37^{\circ} \mathrm{C}$. RIPA cell extracts were subjected to SDS-PAGE and western blot analysis using monoclonal antibody specific for the inducible Hsp70 and $\alpha$-tubulin for normalization. (D) Identification of Hsp70 by flow cytometry.

of parent cells with the plasmid pcDNA-Hsp70-siRNA carrying hsp70-siRNA sequences (Fig. 1A). Several clones were selected after culturing the cells in the presence of the appropriate antibiotic, as described in the Materials and methods. Initially, we detected changes in the cell phenotype, as well as the inability of cells to form tight connections. Furthermore, the cells were elongated and the spaces between them were enlarged. Identical changes were observed in all 3 cell lines under investigation (Fig. 1B).

Half of the plates from each cell line were subjected to heat shock, and the cell extracts were examined by western blot analysis (Fig. 1C) using specific antibody for Hsp70 identification. This analysis revealed that none of the 3 cell lines in the knockdown experiments expressed Hsp70, not even following exposure to heat shock.

Flow cytometric analysis of intracellular Hsp70, using the same anti-Hsp70 antibody and mouse IgG-FITC as an isotype control, was applied to confirm the absence of Hsp70. The absence of Hsp70 expression following Hsp70 gene silencing was confirmed in all 3 cell lines, and representative results in MCF7 cells are illustrated in Fig. 1D.

After the first observations, we aimed to identify factors associated with EMT by the downregulation of Hsp70, the destabilization of the cadherin dimer molecules and the deregulation of the $\beta$-catenin protein, which are known to be involved in the Wnt signaling pathway. 

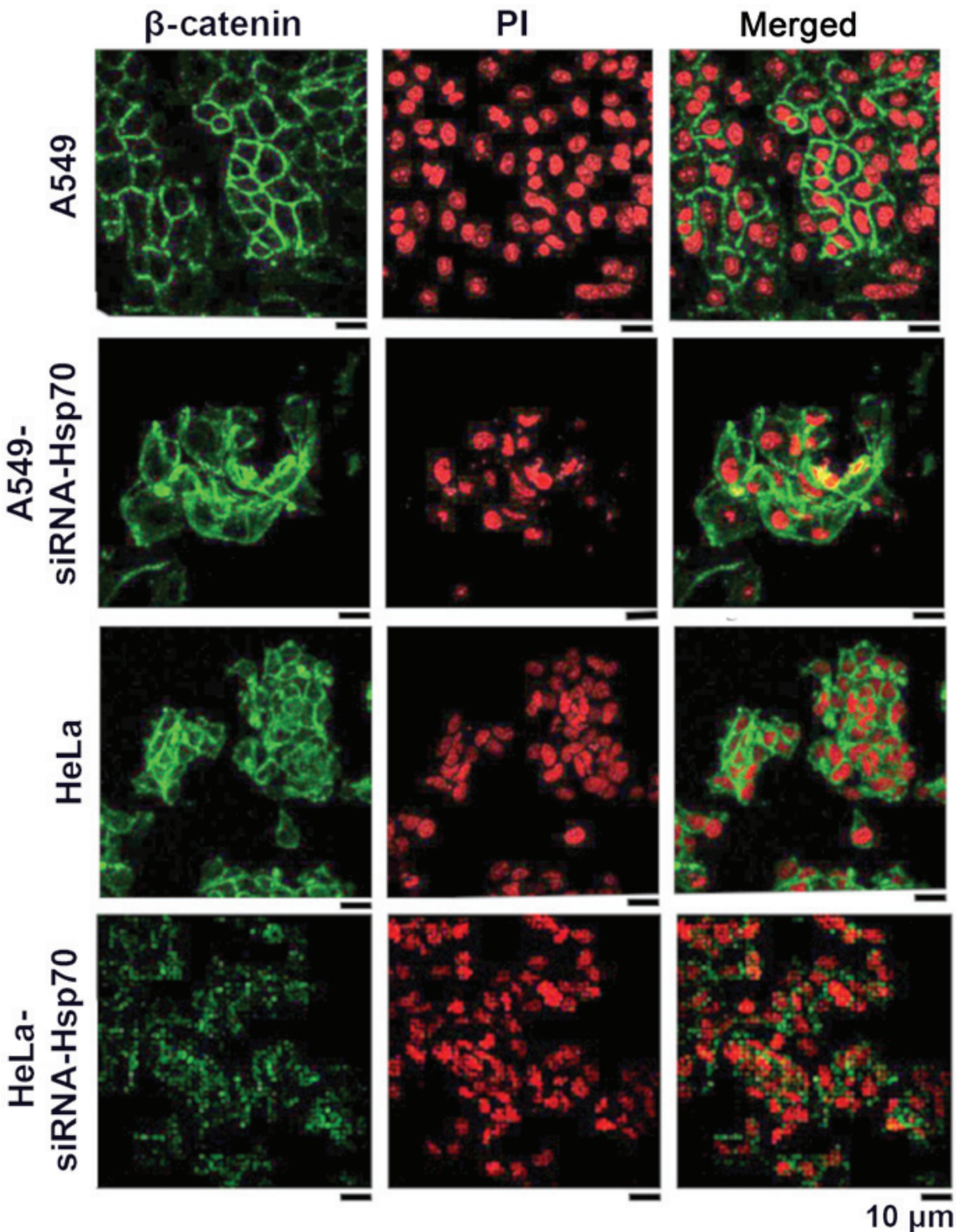

Figure 2. The A549, A549-siRNA-Hsp70, HeLa and HeLa-siRNA-Hsp70 cells were analyzed for $\beta$-catenin by indirect immunofluorescence and confocal microscopy (for more details see in Material and methods). Primary antibodies specific for $\beta$-catenin and secondary antibodies conjugated with FITC were used. The nuclei were stained with propidium iodide (PI). The inserts of the figure are derived from the same experiment. The results were confirmed by 4 different experiments.

Hsp70 is essential for the assembly of intercellular complexes among cadherins and catenins in cancer cells. Several studies have suggested that the $\beta$-catenin signaling pathway plays an important role in EMT. It has already been demonstrated that E-cadherin downregulation releases $\beta$-catenin from the junctions; subsequently, $\beta$-catenin translocates to the nucleus where, in a complex with the TCF cofactor, transactivates several growth-promoting and antiapoptotic genes (54-56). However, there is no direct evidence suggesting a possible crosstalk between $\mathrm{Hsp} 70$ and the $\beta$-catenin pathway to be essential for the establishment of EMT.

Inthis study, toelucidate whether the absence of Hsp70 affects $\beta$-catenin and induces EMT, indirect immunofluorescence was applied to detect $\beta$-catenin in A549 and HeLa control cells, as well as in the corresponding Hsp70-silenced cell lines. In normal cells, $\beta$-catenin is expected to be in a complex with intracellular E-cadherin in epithelial cells. In cells that have acquired mesenchymal-like characteristics, the expression of E-cadherin is downregulated, and the free $\beta$-catenin either accumulates in the cytoplasm, where it is degraded by the proteasomal pathway, or the free $\beta$-catenin translocates to the nucleus where it engages in transcription.

As shown in the HeLa cells (Fig. 2), $\beta$-catenin is mainly located peripherally in the cell, but a small part of it is located within the cytoplasm. This may explain why the absence of E-cadherin results in the release of $\beta$-catenin. In the A549 cells, $\beta$-catenin is only confined to the periphery of the cell, where it combines with the intracellular E-cadherin. Following the gene silencing of Hsp70, free $\beta$-catenin accumulates and diffuses into the cytosol. This indicates that $\beta$-catenin is released from the complexes and diffuses into the surrounding environment. In none of the above-mentioned cases was $\beta$-catenin translocated in the nucleus to act as a transcriptional factor for the induction of EMT under our conditions (Fig. 2). 

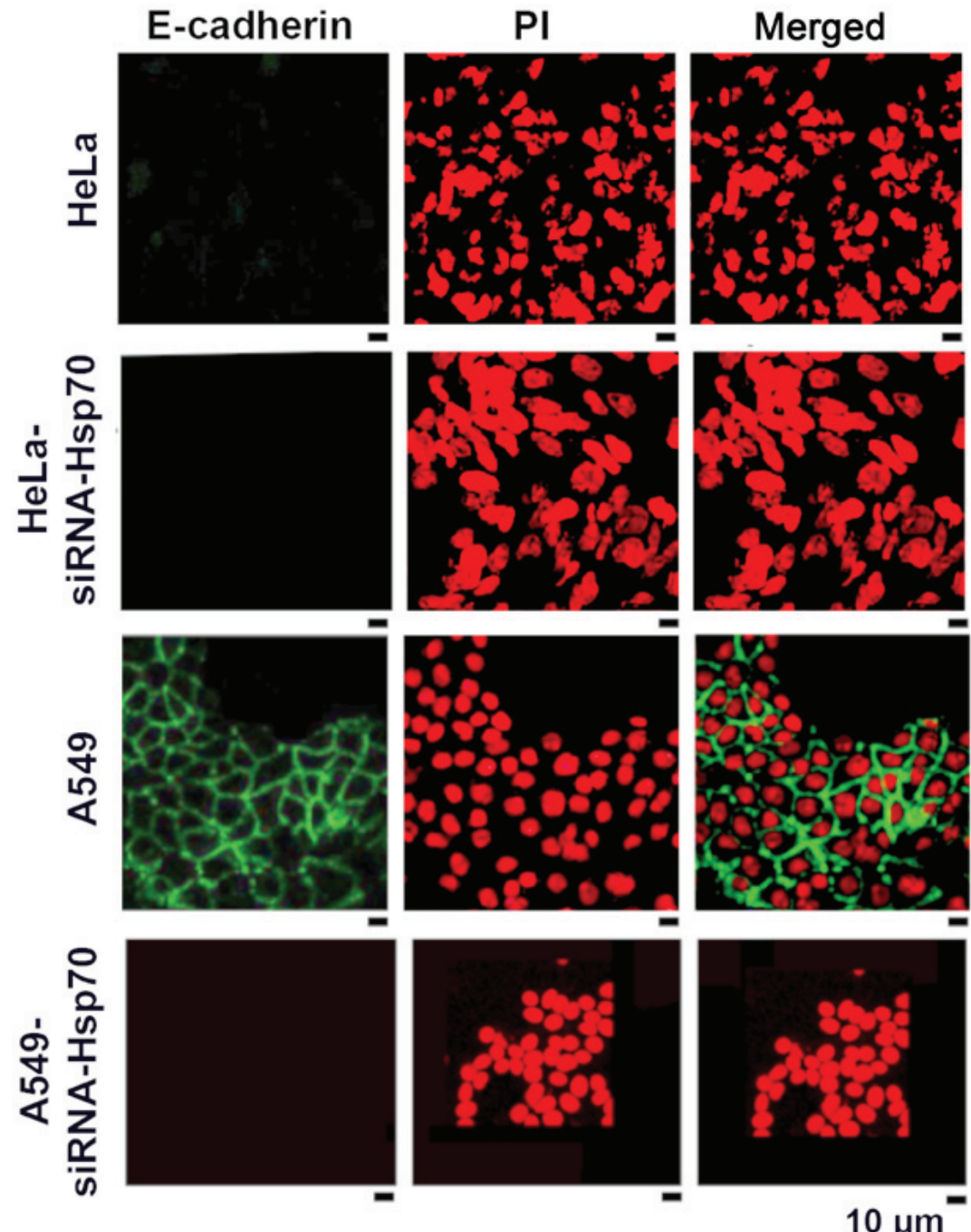

Figure 3. Confocal microscopy of indirect E-cadherin immunofluorescence in HeLa, HeLa-siRNA-Hsp70, A549 and A549-siRNA-Hsp70 cells. Primary antibodies specific for E-cadherin and FITC-conjugated secondary antibodies were used. The nuclei were stained with propidium iodide (PI).

In the HeLa cells, $\beta$-catenin appeared to accumulate somewhat further away from the membrane, indicating that, in these cells, cadherin-catenin complexes have been diminished, resulting in the loss of interactions between adjacent cells.

HSP70 gene silencing reduces the accumulation of E-cadherin. As mentioned above, the loss of Hsp70 led to the disruption of intercellular junctions in various cancer cell lines. One exception among the studied cell lines was the HeLa cells, in which E-cadherin expression and accumulation was absent in the parental cells (Fig. 3). In the literature, E-cadherin has been reported to be an intercellular adhesion molecule that participates in homotypic, calcium-dependent interactions to form adhesion bonds between adjacent cells. The loss of E-cadherin expression is often correlated with the early stages of EMT (57).

We noted that the absence of Hsp70 was accompanied by the deregulation of E-cadherin expression in the tested cell lines, further confirming our hypothesis that the destruction of the cadherin-catenin complexes induces the affected cells to acquire a mesenchymal phenotype. In the HeLa cells, however, this hypothesis could not be confirmed, as the parental HeLa cells did not express E-cadherin (Fig. 3).
As confirmed by the literature,EMT is a process with several intermediate steps (58). In fact, the absence of E-cadherin in the parental HeLa cells suggests that these cells 'escape' from the epithelial phenotype and proceed directly towards the mesenchymal one. On the contrary, E-cadherin accumulates on the membranes of A549 cells (green fluorescence) and disappears in A549-siRNA-Hsp70 cells (Fig. 3). Similar results were obtained in MCF 7 cells (data not shown).

Hsp70 is involved in the anoikis of cancer cells. It is well known that the detachment of a tumor cell from the tumor, or from the neighboring cells in culture, leads to anoikis. The mechanism underlying anoikis is initiated by the destruction of the cadherin-catenin complexes. Of note, our results predicted that the presence of Hsp70 stabilizes the E-cadherin-catenin complexes, as its loss results in the detachment of adjacent cells, as it is shown in Figs. 2 and 3.

Anoikis was investigated in the same cancer cell lines by activating the apoptotic pathway with poly-hema (see Materials and methods). It was observed that, in the cell lines without Hsp70 expression, there was a higher percentage of cell death compared with that in the parental cells (Fig. 4). Of note, the percentage of cells undergoing anoikis was $>50 \%$, 

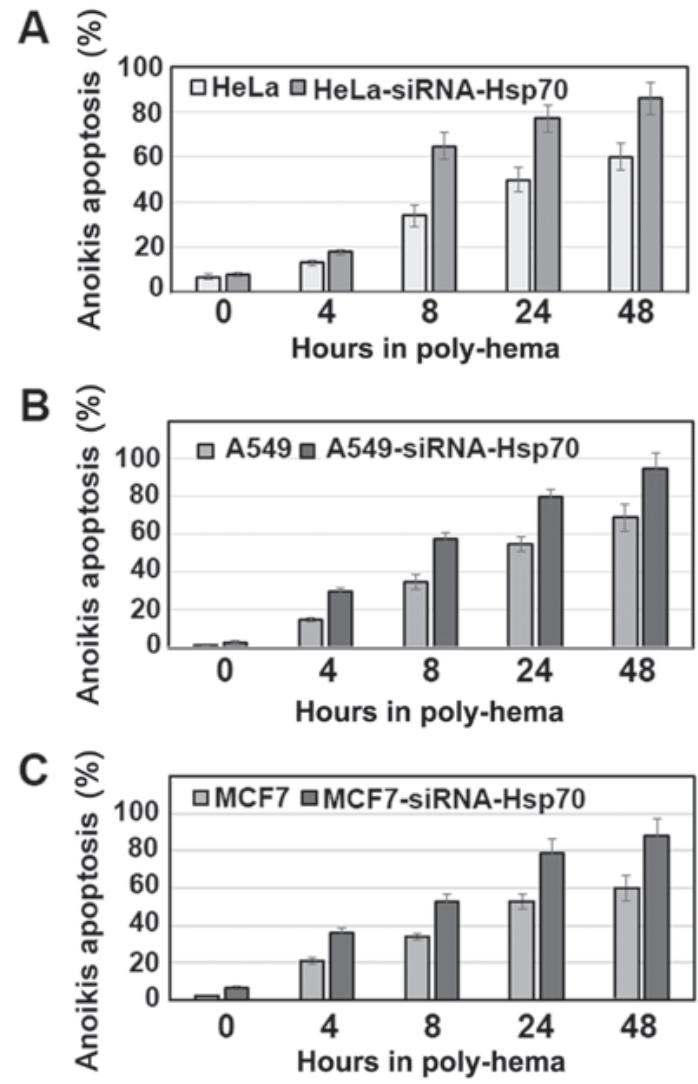

Figure 4.A total of $2 \times 106$ cells $/ 6 \mathrm{~cm}$ petridish of (A) HeLaHeLa-siRNA-Hsp70, (B) A549 and A549-siRNA-Hsp70, and (C) MCF7 and MCF7-siRNA-Hsp70 cells were cultured for $0,4,8,24$ and $48 \mathrm{~h}$ in poly(2-hydroxyethyl methacrylate) (poly-hema)-coated plates. Following staining with propidium iodide and Annexin V fluorescent FITC-conjugated antibody, the samples were analyzed for anoikis apoptosis by flow cytometry. Each point represents the mean value \pm SD of 3 measurements in three separate experiments. In all points, apart from those at $4 \mathrm{~h}$, the P-values were $<0.01$.

even after $8 \mathrm{~h}$. On the contrary, the parental cells, which retained Hsp70 expression, were more resistant and exhibited a significantly lower percentage of apoptosis.

Therefore, if we accept that the cells cultured in the presence of poly-hema proceed directly into the second stage of anoikis, which occurs following their isolation from the rest of the cells, we can then predict that these cells escape death, acquire a mesenchymal phenotype and become migratory and metastatic. The role of Hsp70 until the cells reach their final destination was examined in subsequent experiments.

Absence of Hsp70 causes the cells to acquire a mesenchymal-like phenotype. Furthermore, the probability of cell transition to a mesenchymal phenotype due to the absence of Hsp70 was investigated. Known markers, such as E-cadherin, occludin, N-cadherin, Vimentin and Slug, were used to describe EMT (Fig. 5).

Initially, MCF7 and stably transfected MCF7-siRNA-Hsp70 cancer cells were phenotypically screened and then lysed and subjected to western blot analysis to detect the expression levels of E-cadherin. A substantial reduction of E-cadherin expression, a marker used to indicate the epithelial cell origin, was observed in the MCF7-siRNA-Hsp70 cells compared with parental MCF7 cells. In addition, the cells in which Hsp70 was knocked down had lost their ability to adhere to each other, as observed at the onset of the experimental procedure. However, the MCF7-siRNA-Hsp70 cells, which had lost cell-cell adhesions after Hsp70 knockdown, did not express E-cadherin (Fig. 5). Another indication that the MCF7-siRNA-Hsp70 cells had acquired a mesenchymal phenotype was the increased expression of several mesenchymal markers, such as $\mathrm{N}$-cadherin, vimentin and Slug (Fig. 5). All the above-mentioned results lead to the conclusion that the absence of Hsp70 induces cell transition from an epithelial to a mesenchymal phenotype. To generalize our observations, we conducted similar experiments using the A549 and HeLa cell lines, obtaining identical results. Indeed, the combination of accumulation of $\mathrm{N}$-cadherin, vimentin and Slug proteins, and the decrease in E-cadherin and occludin expression confirmed the transition of cells from epithelial to mesenchymal due to the absence of Hsp70 (Fig. 6). We used $\alpha$-tubulin to ensure that equal protein amounts were loaded from each sample. Therefore, it is clear that Hsp70 silencing converts the cells to mesenchymal and increases cell motility, which are features characterizing metastatic cells.

Finally, the EMT process, which occurred due to the absence of Hsp70, was broadly applied to all the cancer cell lines that have been investigated.

Hsp70 downregulation enhances cancer cell migration ability. The wound healing assay was used to evaluate the migratory capacity of the studied cells (59). Images were captured, cell migration was calculated in the selected areas and data between cell cultures were compared. On plates with confluent cell monolayer, scratches of the same size were created. Cell migration was evaluated by the motility of cells located in the area of scratch. In cell cultures lacking Hsp70, healing was completed more rapidly compared with the control cell cultures (Fig. 7). In particular, HeLa-siRNA-Hsp70 healing occurred within $24 \mathrm{~h}$, as opposed to HeLa cells, in which complete healing was observed after at least $36 \mathrm{~h}$ (Fig. 7A and B). The same experiments were performed in the other cell lines, obtaining similar results. As expected, wound healing occurred more rapidly in the cells lacking Hsp70 (Fig. 7A).

Finally, at $36 \mathrm{~h}$ after scratching, the wound remained open in the Hela cells that expressed Hsp70 at high levels (Fig. 7A and B). Although this result may initially appear contradictory to part of the international bibliography, this is actually not the case, as will be explained in the Discussion below. In order to compare the migration ability of the cancer cell lines under our experimental conditions, the integrity of the junctions between cells formed by adhesion molecules, which are negative factors of migration, should also be taken into consideration (Fig. 8, upper and middle panels). Thus, it may be suggested that the absence of Hsp70 enhances the migratory ability of cells compared with those that retain high expression levels of Hsp70.

Therefore, it may be concluded that Hsp70 gene silencing promotes cancer cells to acquire a mesenchymal phenotype. This change confers an increased migratory ability, as proposed in the hypothetical model (Fig. 8, lower panel).

\section{Discussion}

Hsp70 is known to be a powerful chaperone, whose expression is induced in response to a wide variety of physiological and 
A

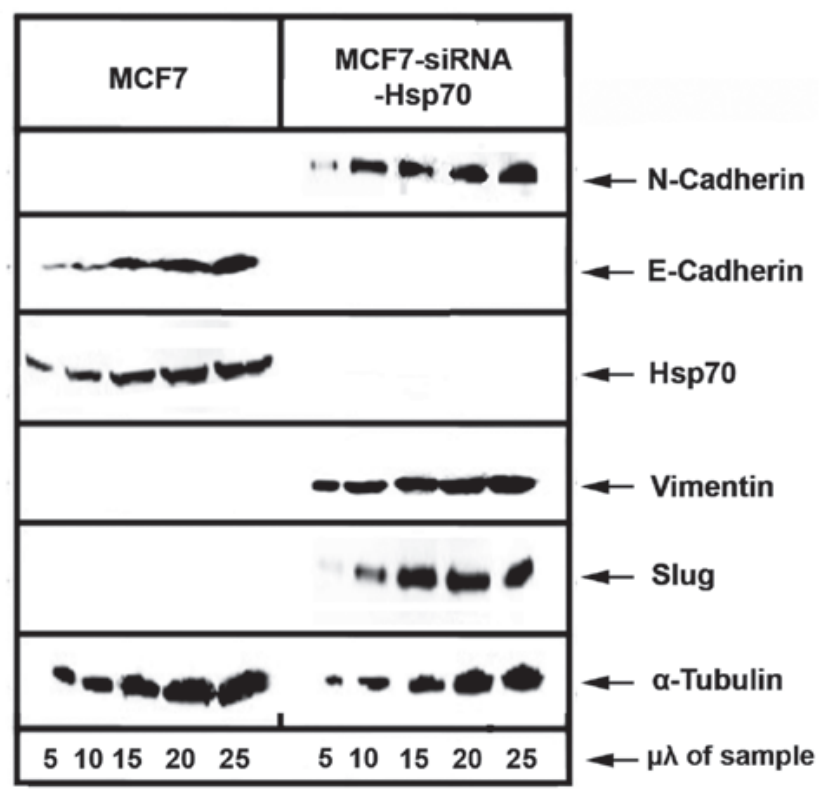

B

\begin{tabular}{|c|}
\hline EMT MARKERS \\
\hline Epithelial markers \\
\hline E-Cadherin \\
Occludin \\
Mesenchymal markers \\
\hline $\begin{array}{l}\text { N-Cadherin } \\
\text { Vimentin } \\
\text { Slug }\end{array}$ \\
\hline
\end{tabular}

Figure 5. (A) MCF-7 parent cells and MCF7 siRNA Hsp70 cells were cultured in $60 \mathrm{~mm}$ plates. RIPA cell extracts were selected and samples of 5, 10, 15, 20, $25 \mu 1$ were analyzed by SDS-PAGE and then subjected to western blot analysis using the corresponding specific antibodies against the arrow-labeled proteins and the chemiluminescence method. (B) The used EMT markers.

A

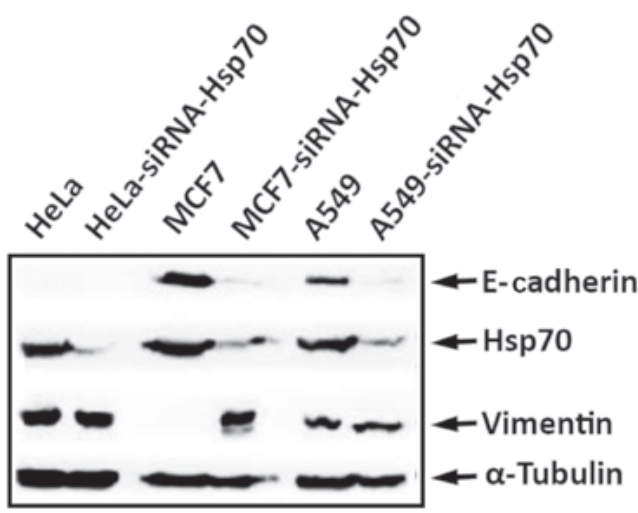

B

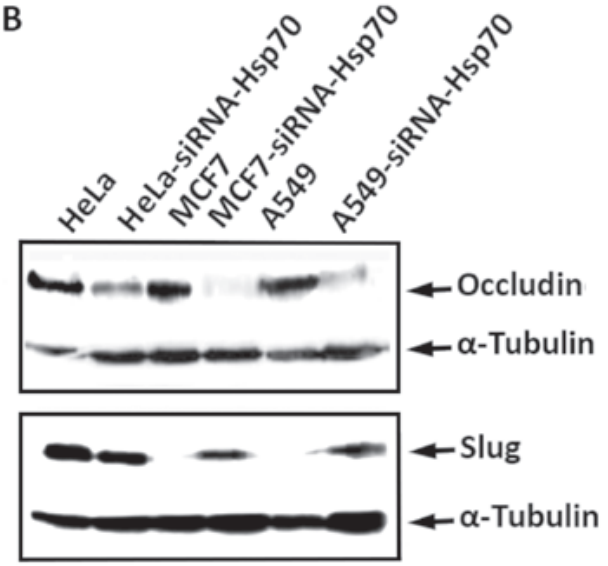

Figure 6. HeLa, HeLa-siRNA-Hsp70, MCF7, MCF7-siRNA-Hsp70, A549, and A549-siRNA-Hsp70 cells were cultured in 60 mm plates. RIPA cell extracts were prepared, analyzed by SDS-PAGE and then subjected to western blot analysis, using specific antibodies for (A) E-cadherin, Hsp70, Vimentin and $\alpha$-tubulin, or (B) against occludin, Slug and $\alpha$-tubulin, and the enhanced chemiluminescence method.

environmental insults, allowing the cell to survive under lethal conditions. Hsp70 has long been considered to be involved in tumorigenesis and cancer metastasis. Its overexpression is observed in a wide range of human cancers and is implicated in tumor cell proliferation, differentiation, invasion, metastasis, death and recognition by the immune system (60). Furthermore, it has been proven that the knockdown of Hsp70 in cervical, bladder, breast and endometrial cancer cell lines reduces invasiveness and propensity for metastasis $(61,62)$.

Although Hsp70 overexpression is considered to contribute to a pre-cancerous environment (35), and that its presence allows the onset and progression of a number of types of cancer (53), there is currently no direct evidence that it causes cancer. In addition, mice overexpressing Hsp70 (14) do not exhibit increased carcinogenesis and survive longer compared with wild-type mice (24). We herein present the dual function of Hsp70 which, on the one hand, contributes to maintaining the integrity of the tumors and, on the other hand, acts against the metastasis of tumor cells in the tumor.

Although available data indicate the important role of Hsp70 in tumorigenesis, the underlying mechanisms remain unclear. The same uncertainty characterizes the involvement of Hsp70 in metastasis. In the present study, existing or newly prepared cancer cell lines were used. The main objective was to investigate the involvement of Hsp70 in metastasis and specifically its role during EMT, a subject that has not been adequately explored. Therefore, morphological and molecular characteristics were selected to indicate EMT status, including the loss of intercellular connections, cell elongation, increased migration and resistance to anoikis (63).

Initially, the appropriate sequence derived from the human Hsp70 gene was used to generate the efficient gene silencing of Hsp70 mRNAs. This sequence was selected by an Oligo Engine program and inserted into a suitable expression vector 

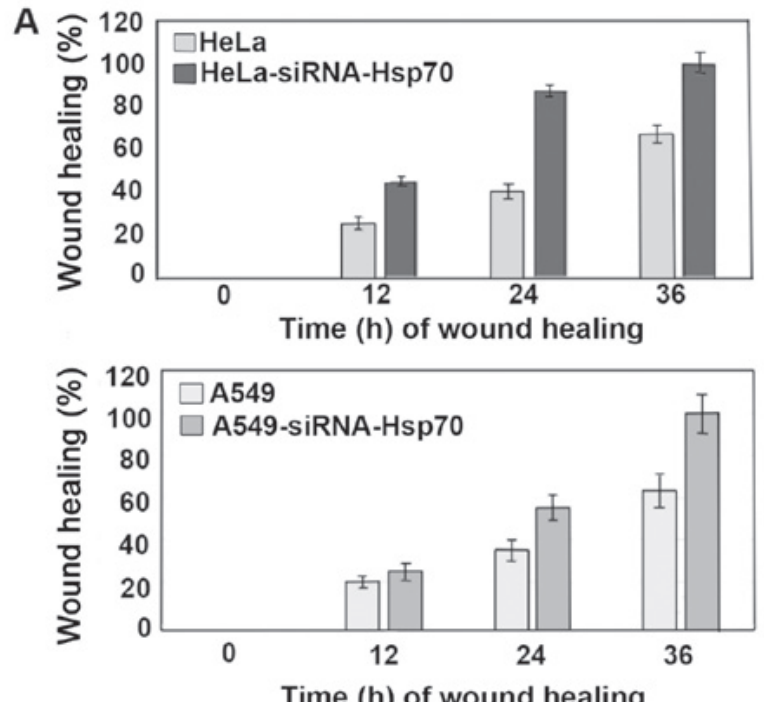

Time (h) of wound healing

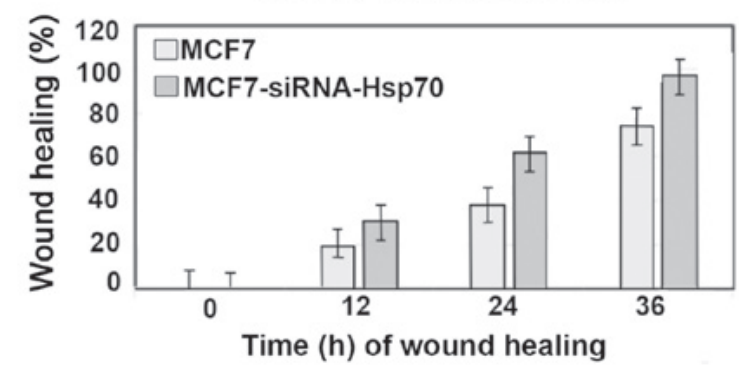

B
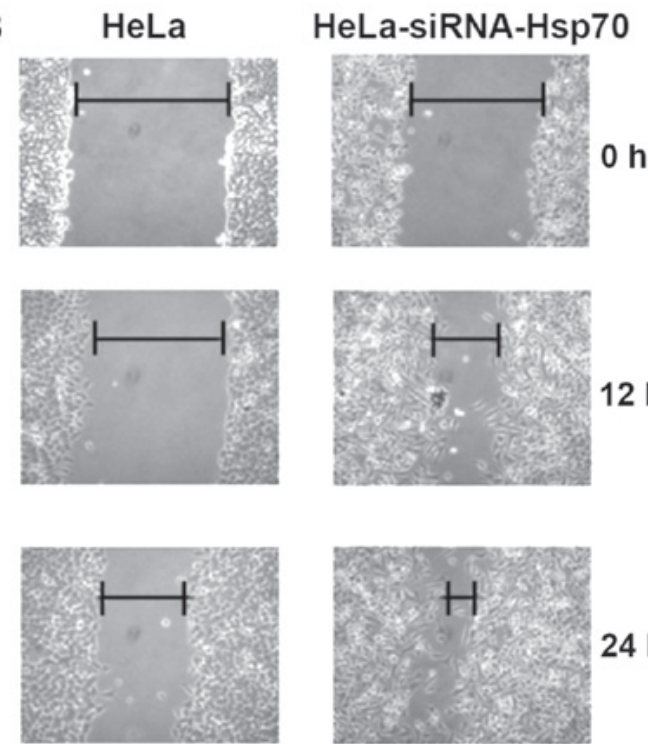

$12 \mathrm{~h}$
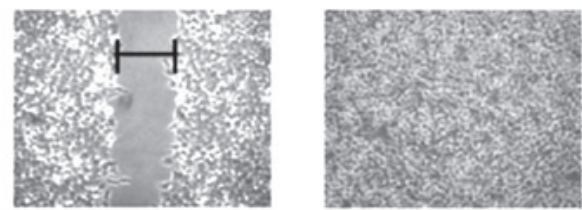

$36 \mathrm{~h}$

Figure 7. Comparison of cell migration of used cell lines with wound healing technique. (A) HeLa and HeLa-siRNA-Hsp70, A549, A549-siRNA-Hsp70, MCF7 and MCF-7-siRNA-Hsp70 were cultured in $6 \mathrm{~cm}$ petri dishes. After scratching the cells, the wound healing was recorded 12,24 and $36 \mathrm{~h}$ later. Cellular migration was calculated as described in the Materials and methods. Each point represents the mean value \pm SD of 3 measurements in 3 separate experiments In all points, except that of $0 \mathrm{~h}$, the P-values were $<0.01$. (B) Photographic example of wound healing using HeLa and HeLa-siRNA-Hsp70 cells at the same time periods.

creating the pSuper-siRNA-Hsp70 plasmid. $\alpha$ plasmid vector carrying a DNA insert was then constructed to express siRNA for gene silencing of Hsp70 named pcDNA3-siRNA-Hsp70. Using this plasmid, stably transfected cell lines were created, named A549-siRNA-Hsp70, MCF7-siRNA-Hsp70 and HeLa-siRNA-Hsp70. In these cell lines, the downregulation of Hsp70 was achieved in $>90 \%$ of the total cell population. The next step would be to discover and comprehend the unique characteristics of the new cell line. Initially, we noted that Hsp70 silencing led to profound changes in the morphology of the cells, which became more elongated and lost their connection to neighboring cells, features typically observed during EMT. EMT is a cellular process that mimics a metastatic step in vivo. Bearing in mind the significant changes in the shape of the cells, we were interested in studying in detail the role of Hsp70 during EMT. It is well known that the sequence of events occurring during metastasis include the dispersion of a cancer cell from the primary to a metastatic site, the dislocation and destruction of intracellular connections, the overcoming of anoikis and the ability of the metastatic cell to migrate from the primary tumor to distant locations.

E-cadherin is classified among the intermediate cell junction proteins associated with the actin filament network via the catenins (64). In immunofluorescence experiments (Fig. 3) using confocal microscopy, it was demonstrate that the absence of Hsp70 caused the disorganization of E-cadherin. As shown in Fig. 2, $\beta$-catenin was markedly concentrated and focused in the membranes of A549 cells. Alongside, in the A549-siRNA-Hsp70 cells, its focus was overturned and exhibited a scattered distribution. Moreover, our findings support the hypothesis depicted in our model (Fig. 8), in which the loss of Hsp70 disrupts the complexes of cadherins with p120, $\alpha$ - and $\beta$-catenins and their association with actin filaments.

In addition, to the best of our knowledge, the present study is the first to provide evidence that loss of Hsp70 sensitizes cells to anoikis, a well-characterized type of cell death, due to their detachment from the cell surface and their isolation from the neighboring cells. It has been well documented that, when epithelial cells are detached from each other and from the ECM, they undergo anoikis. However, further molecular modifications render the cells resistant to anoikis and induce the expression of metastatic characteristics. Previous studies have demonstrated the important contribution of Hsp70 to DNA damage repair, oxidative stress, heat shock and other cellular processes $(12,16)$. In this study, investigating the role of Hsp70 in anoikis in the 3 cancer cell lines demonstrated that Hsp70 gene silencing sensitized cells to death by anoikis, as shown in Fig. 4.

In order to confirm the conversion of epithelial to mesenchymal cells, specific markers of the epithelial and mesenchymal phenotype were selected. In particular, E-cadherin and occludin, which are epithelial markers, and $\mathrm{N}$-cadherin, Vimentin and Slug, which are mesenchymal 

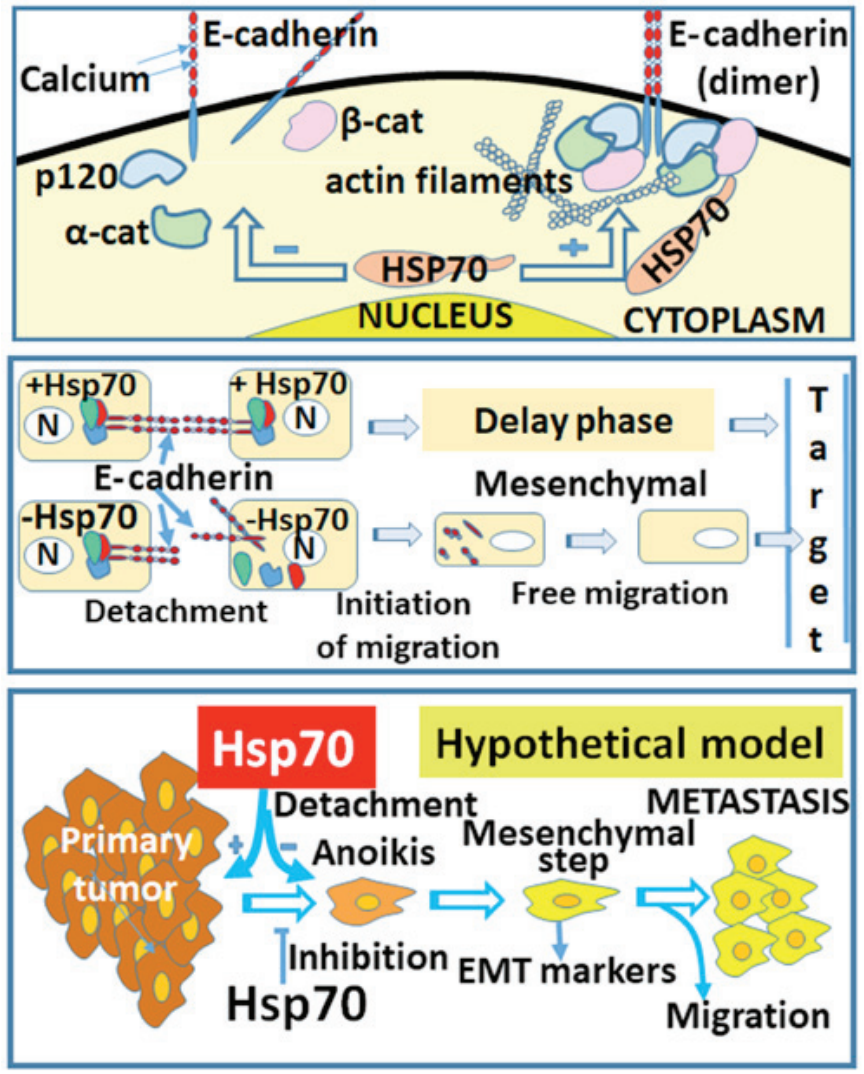

Figure 8. (Upper panel) The presence of Hsp70 in cancer cells contributes to the organization of the E-cadherin dimer. (Intermediate panel) Delay of cancer cells in migration due to anchorages conferring the E-cadherin dimers that are stabilized from Hsp70. (Lower panel) Schematic representation of the model of Hsp70 anti-metastatic function on cancer cells. A hypothetical model (designed by PVe, 2018).

markers, were selected. The cancer cell lines used in the present study acquired a mesenchymal-like phenotype. It was investigated whether the modified cell lines had acquired new characteristic mesenchymal cell properties, such as a higher migratory capacity. As shown in Fig. 7, cancer cells lacking Hsp70 exhibited accelerated migration ability. A possible explanation of cells migrating rapidly was their loss of intercellular connections isolation from the rest of the cell colony. This appears to be achieved by the absence of Hsp70, which contributes to the formation of complexes that serve cellular adhesion. The observed greater mobility when Hsp70 was absent was not due to the different degree of proliferation. Experiments conducted in parallel during the same wound healing period have demonstrated that, at least for the time of wound healing ( $\sim 36 \mathrm{~h}$ after creating the wound), the cells exhibited a similar proliferative capacity (data not shown).

It has heretofore been hypothesized that the ability of cancer cells to promote EMT and subsequent metastasis is increased when Hsp70 is downregulated. A previously published article supporting a similar hypothesis indicate specific mechanisms for the effect of Hsp70 on EMT, which are activated via different stimuli and, more specifically, that Hsp70 can play a protective role against TGF- $\beta 2$-induced EMT-enhancing cell survival (65). Additional articles support the involvement of Hsp70 in the TGF- $\beta$-mediated inhibition of EMT (66). It has also been suggested that HSP70 inhibits the MAPK/EKK and
TGF- $\beta /$ Smad signaling pathways, thus protecting peritoneal mesothelial cells (PMCs) from EMT caused by the advanced glycation end products (AGEs) (67). Furthermore, there are indications that HSP70 decreases the receptor-dependent phosphorylation of Smad2, blocking TGF- $\beta$-induced EMT (68), while inhibiting EMT of PMCs primarily by attenuating Smad3 and Smad4 activation and reducing the release of reactive oxygen species (69). In addition to the aforementioned findings, it may be hypothesized that the inability of cells to construct E-cadherin linkages with neighboring cells, due to the absence of Hsp70, allows cells to migrate more freely. By contrast, as shown in Fig. 8 (middle panel), cells in the presence of Hsp70 retain E-cadherin linkages intact and, therefore, enter a delay phase. This suggestion is enhanced by the previous observation that correlates E-cadherin downregulation with increasing cell migration (44).

The factors contributing to EMT are known to be implicated in several processes, such as occurrence and progression (70-74). In the Hsp70-EMT model, as shown in Fig. 8 (lower panel), Hsp70 appears to be strongly implicated in the regulation of the EMT pathway. In the absence of Hsp70, the cancer cells transitioned to a mesenchymal state, which is known to be highly migratory. Therefore, Hsp70 may represent a promising therapeutic target against cancer metastasis; however, more extensive research is required to confirm the findings of our model.

Finally, given the fact that metastasis is the main cause of treatment failure in cancer and the leading cause of cancer-related mortality (75), further research is required to identify novel inhibitors of metastasis and decode their mechanisms of action to further prolong cancer patient survival (76).

\section{Acknowledgements}

The authors are very thankful to Professor Gerassimos Pagoulatos for his support with the reagents or useful discussions. The authors would also like to thank Dr G. Markopoulos for his technical support.

\section{Funding}

This research was partially co-funded by the European Union and the Hellenic Ministry of Education (program 'Herakleitos') within the 'Operational Program for Education and Initial Vocational Training'. It was also partially supported by a grant to PVe from the Empeirikio Institution, Athens, Greece.

\section{Availability of data and materials}

All data generated or analyzed during this study are included in this published article or are available from the corresponding author on reasonable request.

\section{Authors' contributions}

$\mathrm{CA}$ and $\mathrm{CK}$ were involved in the conceptualization of the study. CA, PK, PVr, AD, SZ and PVe were involved in the methodology. CA, SZ, PVe, PK and PVr were involved in analysis using software. CA, CK, PVe, SZ, PK and PVr were 
involved in data validation. CA, SZ, CK, PVr, PVe and PK were responsible for formal analysis. CA, PVr, PVe, SZ, AD and $\mathrm{PK}$ were involved in the investigative part of the study. PK, PVr, SZ and AD performed the experiments. CA, CK and $\mathrm{PVe}$ provided resources. $\mathrm{CA}, \mathrm{PVe}$ and $\mathrm{PK}$ were involved in data curation. CA, PK, SZ, PVr, PVe, AD and CK were involved in the writing of the manuscript and original draft preparation. CA, PK, SZ, PVr, PVe, AD and CK were involved in the writing, reviewing and editing of the manuscript. CA, $\mathrm{PVr}, \mathrm{PK}$ and PVe were involved in visualization. CA, PK and PVe supervised the study. CA was involved in project administration. CA, PK and PVe were involved in funding acquisition. All the above-mentioned authors participated in the conception and design of the study. All authors have read and approved the final manuscript.

\section{Ethics approval and consent to participate}

Not applicable.

\section{Patient consent for publication}

Not applicable.

\section{Competing interests}

The authors declare that they have no competing interests.

\section{References}

1. Murphy ME: The HSP70 family and cancer. Carcinogenesis 34: 1181-1188, 2013

2. Lindquist $\mathrm{S}$ and Craig EA: The heat-shock proteins. Annu Rev Genet 22: 631-677, 1988.

3. Morimoto RI, Tissières A and Georgopoulos C: The stress response, function of the proteins, and perspectives. In: Stress Proteins in Biology and Medicine. Morimoto RI, Tissières A and Georgopoulos C (eds). Cold Spring Harbor Laboratory Press, Cold Spring Harbor, New York, pp1-36, 1990.

4. Hightower LE: Heat shock, stress proteins, chaperones, and proteotoxicity. Cell 66: 191-197, 1991.

5. Minami Y, Höhfeld J, Ohtsuka K and Hartl F-U: Regulation of the heat-shock protein 70 reaction cycle by the mammalian DnaJ homolog, Hsp40. J Biol Chem 271: 19617-19624, 1996.

6. Huang HC, Sherman MY, Kandror O and Goldberg AL: The molecular chaperone DnaJ is required for the degradation of a soluble abnormal protein in Escherichia coli. J Biol Chem 276: 3920-3928, 2001.

7. Bozidis P, Lazaridis I, Pagoulatos GN and Angelidis CE: Mydj2 as a potent partner of hsc70 in mammalian cells. Eur J Biochem 269: 1553-1560, 2002.

8. Angelidis CE, Lazaridis I and Pagoulatos GN: Aggregation of hsp70 and hsc70 in vivo is distinct and temperature-dependent and their chaperone function is directly related to non-aggregated forms. Eur J Biochem 259: 505-512, 1999.

9. Beckmann RP, Mizzen LE and Welch WJ: Interaction of Hsp 70 with newly synthesized proteins: Implications for protein folding and assembly. Science 248: 850-854, 1990.

10. Saliba RS, Munro PM, Luthert PJ and Cheetham ME: The cellular fate of mutant rhodopsin: Quality control, degradation and aggresome formation. J Cell Sci 115: 2907-2918, 2002.

11. Chirico WJ, Waters MG and Blobel G: $70 \mathrm{~K}$ heat shock related proteins stimulate protein translocation into microsomes. Nature 332: 805-810, 1988

12. Kotoglou P, Kalaitzakis A, Vezyraki P, Tzavaras T, Michalis LK, Dantzer F, Jung JU and Angelidis C: Hsp70 translocates to the nuclei and nucleoli, binds to XRCC1 and PARP-1, and protects HeLa cells from single-strand DNA breaks. Cell Stress Chaperones 14: 391-406, 2009.
13. Angelidis CE, Lazaridis I and Pagoulatos GN: Constitutive expression of heat-shock protein 70 in mammalian cells confers thermoresistance. Eur J Biochem 199: 35-39, 1991.

14. Angelidis C, Nova C, Lazaridis I, Kontoyiannis D, Kollias G and Pagoulatos GN: Overexpression of HSP70 in transgenic mice results in increased cell thermotolerance. Transgenics 2: 111-117, 1996.

15. Jäättelä M, Wissing D, Kokholm K, Kallunki T and Egeblad M: Hsp70 exerts its anti-apoptotic function downstream of caspase3-like proteases. EMBO J 17: 6124-6134, 1998.

16. Damalas A, Velimezi G, Kalaitzakis A, Liontos M Papavassiliou AG, Gorgoulis V and Angelidis C: Loss of p14(ARF) confers resistance to heat shock- and oxidative stressmediated cell death by upregulating $\beta$-catenin. Int J Cancer 128 : 1989-1995, 2011.

17. Cummings CJ; Cummings CJ1: Sun Y, Opal P, Antalffy B, Mestril R, Orr HT, Dillmann WH, and Zoghbi HY: Overexpression of inducible HSP70 chaperone suppresses neuropathology and improves motor function in SCA1 mice. Hum Mol Genet 10: 1511-1518, 2001.

18. Adachi H, Katsuno M, Minamiyama M, Sang C, Pagoulatos G, Angelidis C, Kusakabe M, Yoshiki A, Kobayashi Y, Doyu M, et al: Heat shock protein 70 chaperone overexpression ameliorates phenotypes of the spinal and bulbar muscular atrophy transgenic mouse model by reducing nuclear-localized mutant androgen receptor protein. J Neurosci 23: 2203-2211, 2003.

19. Scott MD and Frydman J: Aberrant protein folding as the molecular basis of cancer. Methods Mol Biol 232: 67-76, 2003.

20. Mosser DD and Morimoto RI: Molecular chaperones and the stress of oncogenesis. Oncogene 23: 2907-2918, 2004.

21. Ammon-Treiber S, Grecksch G, Angelidis C, Vezyraki P, Höllt V and Becker A: Emotional and learning behaviour in mice overexpressing heat shock protein 70. Neurobiol Learn Mem 90: 358-364, 2008.

22. Plumier JC, Ross BM, Currie RW, Angelidis CE, Kazlaris H, Kollias G and Pagoulatos GN: Transgenic mice expressing the human heat shock protein 70 have improved post-ischemic myocardial recovery. J Clin Invest 95: 1854-1860, 1995.

23. Lysitsas DN, Katsouras CS, Papakostas JC, Toumpoulis IK, Angelidis C, Bozidis P, Thomas CG, Seferiadis K, Psychoyios N, Frillingos S, et al: Antirestenotic effects of a novel polymercoated d-24851 eluting stent. Experimental data in a rabbit iliac artery model. Cardiovasc Intervent Radiol 30: 1192-1200, 2007.

24. Naka K K, Vezyraki P, Kalaitzakis A, Zerikiotis S, Michalis L and Angelidis C: Hsp70 regulates the doxorubicin-mediated heart failure in Hsp70-transgenic mice. Cell Stress Chaperones 19: 853-864, 2014.

25. Kyrou IE, Papakostas JC, Ioachim E, Koulouras V, Arnaoutoglou E, Angelidis C and Matsagkas MI: Early ischaemic preconditioning of spinal cord enhanced the binding profile of heat shock protein 70 with neurofilaments and promoted its nuclear translocation after thoraco-abdominal aortic occlusion in pigs. Eur J Vasc Endovasc Surg 43: 408-414, 2012.

26. Ninomiya H, Ohgami N, Oshino R, Kato M, Ohgami K, Li X, Shen D, Iida M, Yajima I, Angelidis CE, et al: Increased expression level of Hsp70 in the inner ears of mice by exposure to low frequency noise. Hear Res 363: 49-54, 2018.

27. Morano KA: New tricks for an old dog: The evolving world of Hsp70. Ann N Y Acad Sci 1113: 1-14, 2007.

28. Dudeja V, Mujumdar N, Phillips P, Chugh R, Borja-Cacho D, Dawra RK, Vickers SM and Saluja AK: Heat shock protein 70 inhibits apoptosis in cancer cells through simultaneous and independent mechanisms. Gastroenterology 136: 1772-1782, 2009.

29. Wei YQ, Zhao X, Kariya Y, Teshigawara K and Uchida A: Inhibition of proliferation and induction of apoptosis by abrogation of heat-shock protein (HSP) 70 expression in tumor cells. Cancer Immunol Immunother 40: 73-78, 1995.

30. Nylandsted J, Rohde M, Brand K, Bastholm L, Elling F and Jäättelä M: Selective depletion of heat shock protein 70 (Hsp70) activates a tumor-specific death program that is independent of caspases and bypasses Bcl-2. Proc Natl Acad Sci USA 97: 7871-7876, 2000.

31. Nylandsted J, Wick W, Hirt UA, Brand K, Rohde M, Leist M, Weller M and Jäättelä M: Eradication of glioblastoma, and breast and colon carcinoma xenografts by Hsp70 depletion. Cancer Res 62: 7139-7142, 2002.

32. Frisch SM and Francis H: Disruption of epithelial cell-matrix interactions induces apoptosis. J Cell Biol 124: 619-626, 1994.

33. Guan JL and Shalloway D: Regulation of focal adhesionassociated protein tyrosine kinase by both cellular adhesion and oncogenic transformation. Nature 358: 690-692, 1992. 
34. Ruoslahti E and Reed JC: Anchorage dependence, integrins, and apoptosis. Cell 77: 477-478, 1994.

35. Jäättelä M: Escaping cell death: Survival proteins in cancer. Exp Cell Res 248: 30-43, 1999

36. Beere HM, Wolf BB, Cain K, Mosser DD, Mahboubi A, Kuwana T, Tailor P, Morimoto RI, Cohen GM and Green DR: Heat-shock protein 70 inhibits apoptosis by preventing recruitment of procaspase-9 to the Apaf-1 apoptosome. Nat Cell Biol 2: 469-475, 2000

37. Kalluri R and Neilson EG: Epithelial-mesenchymal transition and its implications for fibrosis. J Clin Invest 112: 1776-1784, 2003.

38. Peinado H, Olmeda D and Cano A: Snail, Zeb and bHLH factors in tumour progression: An alliance against the epithelial phenotype? Nat Rev Cancer 7: 415-428, 2007.

39. Huang RY, Guilford P and Thiery JP: Early events in cell adhesion and polarity during epithelial-mesenchymal transition. J Cell Sci 125: 4417-4422, 2012.

40. Yilmaz M and Christofori G: Mechanisms of motility in metastasizing cells. Mol Cancer Res 8: 629-642, 2010.

41. Yilmaz M and Christofori G: Yilmaz M1and and Christofori G EMT, the cytoskeleton, and cancer cell invasion. Cancer Metastasis Rev 28: 15-33, 2009.

42. Niehrs C: The complex world of WNT receptor signalling. Nat Rev Mol Cell Biol 13: 767-779, 2012.

43. Kourtidis A, Ngok SP and Anastasiadis PZ: p120 catenin: An essential regulator of cadherin stability, adhesion-induced signaling, and cancer progression. Prog Mol Biol Transl Sci 116 : 409-432, 2013

44. Hajra KM and Fearon ER: Cadherin and catenin alterations in human cancer. Genes Chromosomes Cancer 34: 255-268, 2002.

45. Wheelock MJ, Shintani Y, Maeda M, Fukumoto Y and Johnson KR: Cadherin switching. J Cell Sci 121: 727-735, 2008.

46. Theveneau E and Mayor R: Cadherins in collective cell migration of mesenchymal cells. Curr Opin Cell Biol 24: 677-684, 2012.

47. Franke WW, Grund C, Kuhn C, Jackson BW and Illmensee K Formation of cytoskeletal elements during mouse embryogenesis. III. Primary mesenchymal cells and the first appearance of vimentin filaments. Differentiation 23: 43-59, 1982.

48. McInroy L and Määttä A: Down-regulation of vimentin expression inhibits carcinoma cell migration and adhesion. Biochem Biophys Res Commun 360: 109-114, 2007.

49. Vuoriluoto K, Haugen H, Kiviluoto S, Mpindi JP, Nevo J, Gjerdrum C, Tiron C, Lorens JB and Ivaska J: Vimentin regulates EMT induction by Slug and oncogenic $\mathrm{H}-\mathrm{R}$ as and migration by governing Axl expression in breast cancer. Oncogene 30: $1436-1448,2011$

50. Sun Y, Song GD, Sun N, Chen JQ and Yang SS: Slug overexpression induces stemness and promotes hepatocellular carcinoma cell invasion and metastasis. Oncol Lett 7: 1936-1940, 2014.

51. Angelidis CE, Lazaridis I and Pagoulatos GN: Specific inhibition of simian virus 40 protein synthesis by heat and arsenite treatment. Eur J Biochem 172: 27-34, 1988

52. Doulias P-T, Kotoglou P, Tenopoulou M, Keramisanou D, Tzavaras T, Brunk U, Galaris D and Angelidis C: Involvement of heat shock protein-70 in the mechanism of hydrogen peroxideinduced DNA damage: The role of lysosomes and iron. Free Radic Biol Med 42: 567-577, 2007.

53. Gabai VL, Yaglom JA, Wang Y, Meng L, Shao H, Kim G, Colvin T, Gestwicki J and Sherman MY: Anti-cancer effects of targeting Hsp70 in tumor stromal cells. Cancer Res 76: 59265932,2016

54. Novak A and Dedhar S: Signaling through beta-catenin and Lef/Tcf. Cell Mol Life Sci 56: 523-537, 1999.

55. Chaw SY, Abdul Majeed A, Dalley AJ, Chan A, Stein S and Farah CS: Epithelial to mesenchymal transition (EMT) biomarkers - E-cadherin, beta-catenin, APC and Vimentin - in oral squamous cell carcinogenesis and transformation. Oral Oncol 48: 997-1006, 2012.

56. Mao J, Hu X, Xiao Y, Yang C, Ding Y, Hou N, Wang J, Cheng H and Zhang X: Overnutrition stimulates intestinal epithelium proliferation through $\beta$-catenin signaling in obese mice. Diabetes 62: 3736-3746, 2013.
57. Cowin P, Rowlands TM and Hatsell SJ; Cowin P1: Rowlands TM and Hatsell SJ: Cadherins and Catenins in breast cancer. Curr Opin Cell Biol 17: 499-508, 2005.

58. Wu CY, Tsai YP, Wu MZ, Teng SC and Wu KJ: Epigenetic reprogramming and post-transcriptional regulation during the epithelial-mesenchymal transition. Trends Genet 28: 454-463, 2012.

59. Rodriguez LG, Wu X and Guan JL: Wound-healing assay. Methods Mol Biol 294: 23-29, 2005.

60. Ciocca DR and Calderwood SK: Heat shock proteins in cancer: Diagnostic, prognostic, predictive, and treatment implications. Cell Stress Chaperones 10: 86-103, 2005.

61. Garg M, Kanojia D, Seth A, Kumar R, Gupta A, Surolia A and Suri A: Heat-shock protein 70-2 (HSP70-2) expression in bladder urothelial carcinoma is associated with tumour progression and promotes migration and invasion. Eur J Cancer 46: 207-215, 2010.

62. Teng Y, Ngoka L, Mei Y, Lesoon L and Cowell JK: HSP90 and HSP70 proteins are essential for stabilization and activation of WASF3 metastasis-promoting protein. J Biol Chem 287: 10051-10059, 2012.

63. Moreno-Bueno G, Peinado H, Molina P, Olmeda D, Cubillo E, Santos V, Palacios J, Portillo F and Cano A: The morphological and molecular features of the epithelial-to-mesenchymal transition. Nat Protoc 4: 1591-1613, 2009.

64. Buxton RS and Magee AI: Structure and interactions of desmosomal and other cadherins. Semin Cell Biol 3: 157-167, 1992.

65. Banh A, Deschamps PA, Vijayan MM, Sivak JG and West-Mays JA: The role of Hsp70 and Hsp90 in TGF- $\beta$-induced epithelial-to-mesenchymal transition in rat lens epithelial explants. Mol Vis 13: 2248-2262, 2007.

66. Yun CH, Yoon SY, Nguyen TT, Cho HY, Kim TH, Kim ST, Kim BC, Hong YS, Kim SJ and Lee HJ: Geldanamycin inhibits TGF- $\beta$ signaling through induction of Hsp70. Arch Biochem Biophys 495: 8-13, 2010

67. Yang J, Zhu T, Liu X, Zhang L, Yang Y, Zhang J and Guo M: Heat shock protein 70 protects rat peritoneal mesothelial cells from advanced glycation end-products-induced epithelial-tomesenchymal transition through mitogen activated protein kinases/extracellular signal-regulated kinases and transforming growth factor- $\beta /$ Smad pathways. Mol Med Rep 11: 4473-4481, 2015.

68. Li Y, Kang X and Wang Q: HSP70 decreases receptor-dependent phosphorylation of Smad 2 and blocks TGF- $\beta$-induced epithelialmesenchymal transition. J Genet Genomics 38: 111-116, 2011.

69. Liu J, Bao J, Hao J, Peng Y and Hong F: HSP70 inhibits high glucose-induced Smad3 activation and attenuates epithelial-tomesenchymal transition of peritoneal mesothelial cells. Mol Med Rep 10: 1089-1095, 2014.

70. Guarino M, Rubino B and Ballabio G: The role of epithelial-mesenchymal transition in cancer pathology. Pathology 39: 305-318, 2007.

71. Mani SA, Guo W, Liao MJ, Eaton EN, Ayyanan A, Zhou AY Brooks M, Reinhard F, Zhang CC, Shipitsin M, et al: The epithelial-mesenchymal transition generates cells with properties of stem cells. Cell 133: 704-715, 2008

72. Kalluri R and Weinberg RA: The basics of epithelial-mesenchymal transition. J Clin Invest 119: 1420-1428, 2009.

73. Klymkowsky MW and Savagner P: Epithelial-mesenchymal transition: A cancer researcher's conceptual friend and foe. Am J Pathol 174: 1588-1593, 2009.

74. Thiery JP: Epithelial-mesenchymal transitions in cancer onset and progression. Bull Acad Natl Med 193: 1969-1979, 2009 (In French).

75. Steeg PS: Targeting metastasis. Nat Rev Cancer 16: 201-218, 2016.

76. Qian CN, Mei Y and Zhang J: Cancer metastasis: Issues and challenges. Chin J Cancer 36: 38, 2017. Attribution-NonCommercial-NoDerivatives 4.0 International (CC BY-NC-ND 4.0) License. 